Supporting Information:

\title{
Polymorphism in Solid Dispersions
}

Karina Sanabria Ortiz, ${ }^{1,2}$ José R. Hernández Espinell,,$^{, 2}$ Desire Ortiz Torres, ${ }^{1,2}$ Vilmalí Lopéz-Mejías, ${ }^{12 *}$ and Torsten Stelzer ${ }^{2^{3 *}}$

'Department of Chemistry, University of Puerto Rico, Río Piedras Campus, San Juan, Puerto Rico, 00931, USA

${ }^{2}$ Crystallization Design Institute, Molecular Sciences Research Center, University of Puerto Rico, San Juan, PR 00926, USA

${ }^{3}$ Department of Pharmaceutical Sciences, University of Puerto Rico, Medical Sciences Campus, San Juan, Puerto Rico, 00936, USA

*E-mail: vilmali.lopez@upr.edu (Dr. Vilmalí López-Mejías)

*E-mail: torsten.stelzer@upr.edu (Dr. Torsten Stelzer) 
Table of Contents

1. MOLECULAR STRUCTURES \& PACKING DIAGRAMS 3

2. THERMODYNAMIC MODELING PARAMETERS 3

3. POWDER X-RAY DIFFRACTION (PXRD) 4

3.1 PHYSICAL MIXTURES

3.2 SOLVENT EVAPORATION METHOD

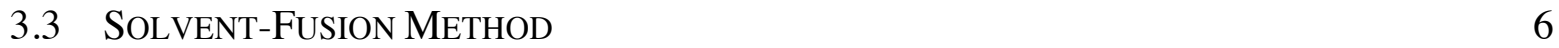

$\begin{array}{lll}3.4 & \text { FuSION METHOD } & 7\end{array}$

4. FOURIER TRANSFORM INFRARED (FTIR) SPECTROSCOPY

4.1 SOLVENT EVAPORATION METHOD $\quad 9$

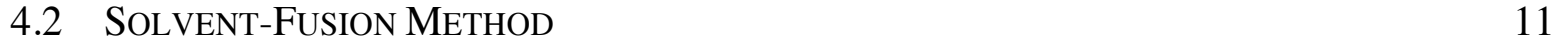

$\begin{array}{lll}4.3 & \text { Fusion METHOD } & 12\end{array}$

5. PHASE DIAGRAM 13

6. AVERAGE RELATIVE DEVIATION (ARD\%) 13

7. SUPERCOOLING OF SPONTANEOUS NUCLEATION IN FUSION

$\begin{array}{ll}\text { METHOD } & 14\end{array}$

8. REFERENCES 14 


\section{Molecular Structures \& Packing Diagrams}<smiles>O=C(O)c1ccccc1Nc1cccc(C(F)(F)F)c1</smiles>

Flufenamic Acid (FFA)<smiles>CC(O)CO[18OH]</smiles>

\section{Polyethylene Glycol} (PEG)

Figure S1. Molecular structures of flufenamic acid (FFA, left) and polyethylene glycol (PEG, right).

FFA I

FFA II

FFA III

FFA IV
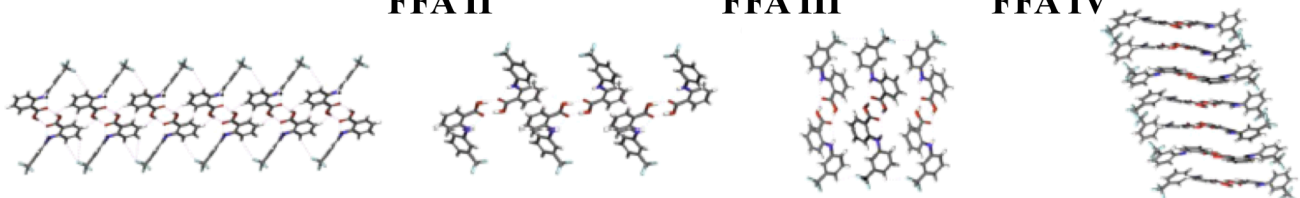

FFA V

FFA VI

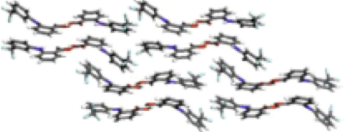

FFA VII
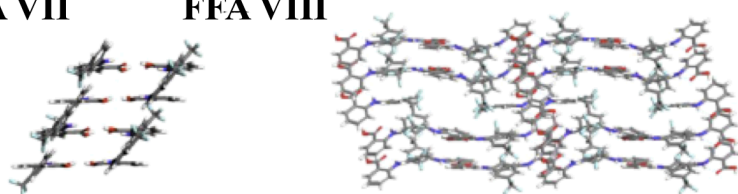

Figure S2. Molecular packing and hydrogen-bonding motifs of FFA polymorphs: FFA I viewed along the a-axis, FFA II viewed along the a-axis, FFA III viewed along the $a$-axis, FFA IV viewed along the $a$-axis, FFA $V$ viewed along the $b$-axis, FFA VI viewed along the $a$-axis, FFA VII viewed along the $b$-axis, and FFA VIII, ordered molecules only, viewed perpendicular to the $b c$-plane.'

\section{Thermodynamic Modeling Parameters}

Table 1. Summary of parameters used for flufenamic acid (FFA) and PEG 10,000 (PEG) to calculate the phase diagrams employing the Lacoulonche model.

\begin{tabular}{|c|c|c|c|c|c|}
\hline $\begin{array}{c}\text { Componen } \\
\mathrm{t}\end{array}$ & $\begin{array}{c}\text { Molecular } \\
\text { weight, } \mathrm{M}_{w} \\
(\mathrm{~g} / \mathrm{mol})\end{array}$ & $\begin{array}{c}\text { Melting point, } \\
\mathrm{T}_{m}\left({ }^{\circ} \mathrm{C}\right)\end{array}$ & $\begin{array}{c}\text { Heat of } \\
\text { fusion, } \Delta \mathrm{H}_{f} \\
(\mathrm{~J} / \mathrm{g})\end{array}$ & $\begin{array}{c}\text { Density, } \\
\rho\left(\mathrm{g} / \mathrm{cm}^{3}\right)\end{array}$ & $\begin{array}{c}\text { Molar volume, } \\
\mathrm{V}_{m}\left(\mathrm{~cm}^{3} / \mathrm{mol}\right)\end{array}$ \\
\hline FFA III & 281.2 & $126.3 \pm 0.2^{\mathrm{a}}$ & $25.4 \pm 2^{\mathrm{a}}$ & 1.50 & $187.4^{\mathrm{a}}$ \\
\hline PEG & 10,000 & $60.59 \pm 0.01^{\mathrm{a}}$ & $180.9 \pm 0.4^{*}$ & $1.20^{2}$ & $8333.3^{\mathrm{a}}$ \\
\hline
\end{tabular}

The melting point $\left(\mathrm{T}_{\mathrm{m}}\right)$ and the heat of fusion $\left(\Delta \mathrm{H}_{\mathrm{f}}\right)$ were determined experimentally within this work and the molar volume $\left(\mathrm{V}_{\mathrm{m}}\right)$ was calculated utilizing Equation (3) in the manuscript. 


\section{Powder X-ray Diffraction (PXRD)}

Figures S3-S10 show the PXRDs of the FFA III-PEG and FFA I-PEG physical mixtures and the resulting crystalline solid dispersons (CSDs) obtained after each preparation method under each of the experimental conditions. Simulated PXRDs were extracted from the crystallographic information files (CIF files) obtained from the Cambridge Structural Database for FFA I (Reference Code $=$ FPAMCA11, blue $),{ }^{\prime}$ III $($ Reference Code $=$ FPAMCA, green $),{ }^{3}$ and IV (Reference Code= FPAMCA15, black).' The experimental powder X-ray diffractogram of PEG is shown for comparison.

\subsection{Physical Mixtures}

A)

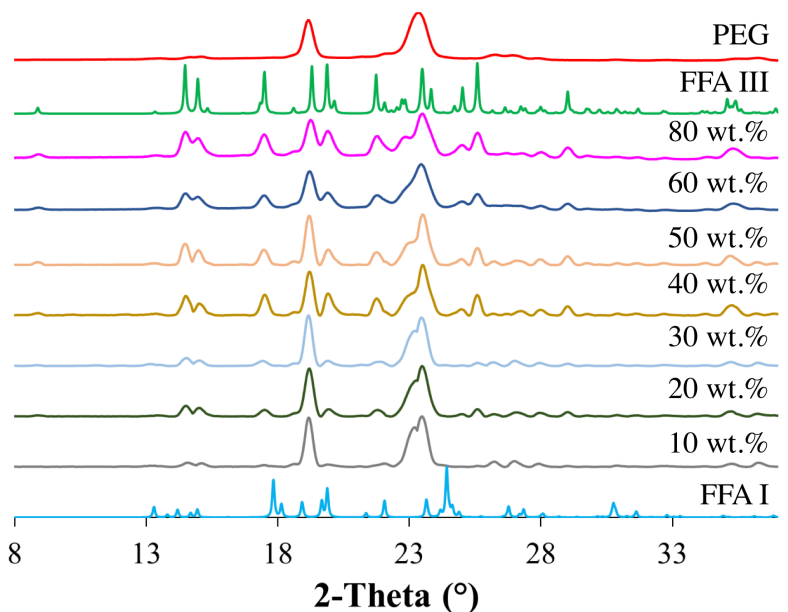

B)

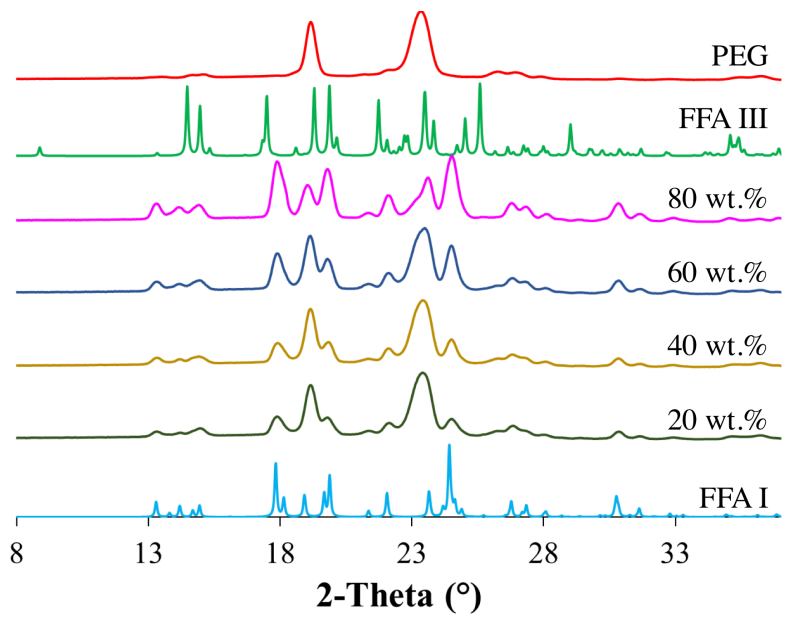

Figure S3. PXRD of physical mixtures prepared for A) FFA III-PEG and B) FFA I-PEG. From bottom to top: simulated PXRD of FFA I (Reference Code = FPAMCA11, blue), experimental PXRD of physical mixtures (various colors), simulated PXRD of FFA III (Reference Code $=$ FPAMCA, green), and experimental PXRD of PEG (red). 


\subsection{Solvent Evaporation Method}

A)

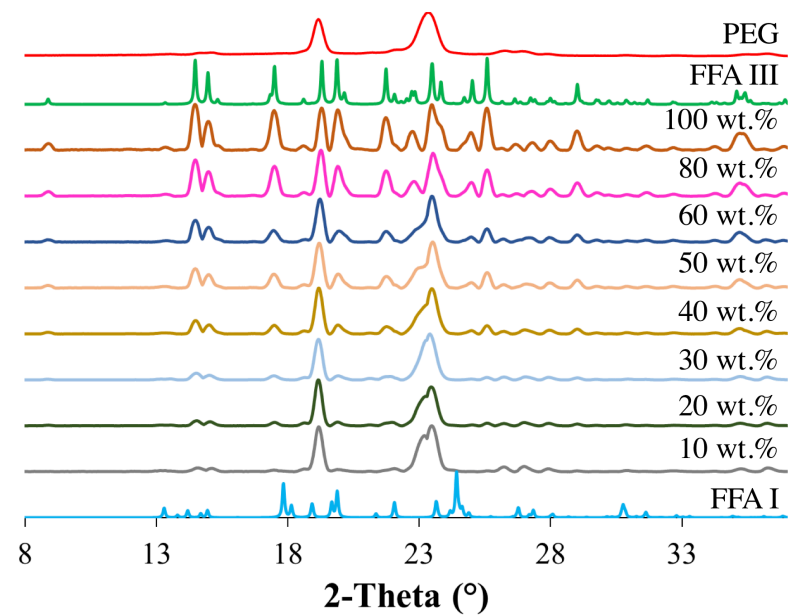

B)

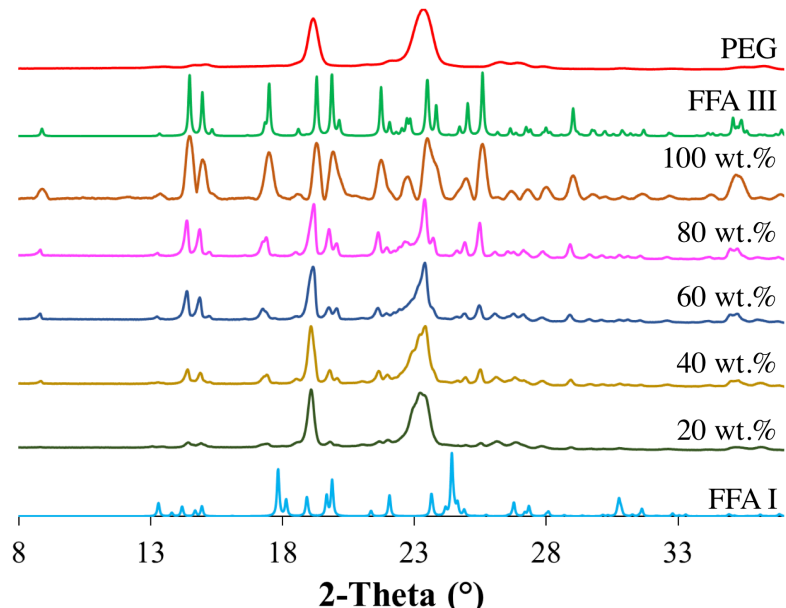

Figure S4. PXRD for CSDs obtained by the solvent evaporation method in ethanol using a fast evaporation rate at $40{ }^{\circ} \mathrm{C}$ starting with A) FFA III or B) FFA I. From bottom to top: simulated PXRD of FFA I (Reference Code = FPAMCA11, blue), experimental PXRD of treated CSDs (various colors), simulated PXRD of FFA III (Reference Code $=$ FPAMCA, green) ${ }^{3}$ and experimental PXRD of PEG (red).

A)

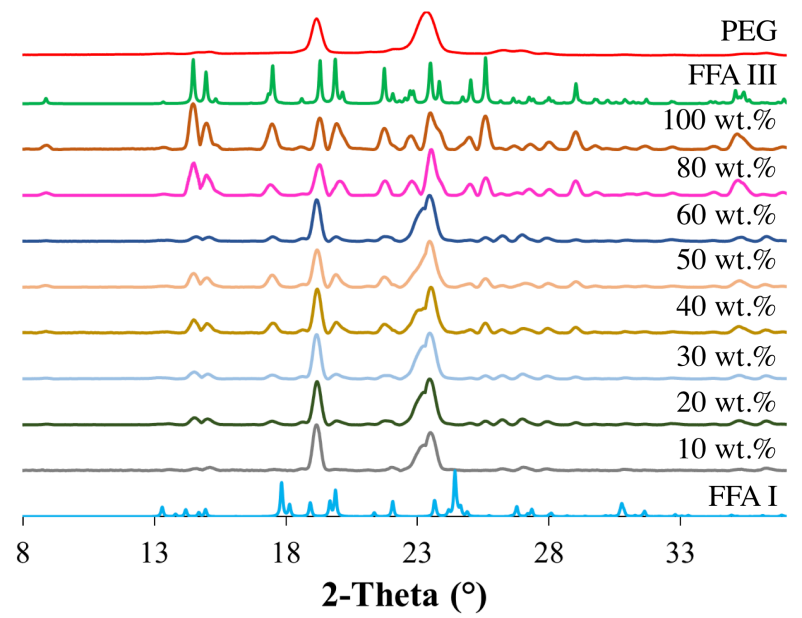

B)

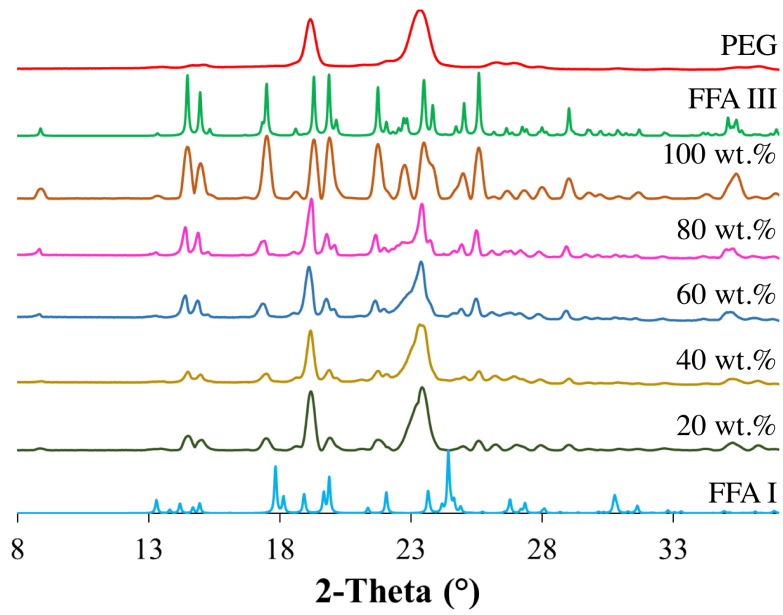

Figure S5. PXRD for CSDs obtained by the solvent evaporation method in ethanol using a slow evaporation rate at $40{ }^{\circ} \mathrm{C}$ starting with A) FFA III or B) FFA I. From bottom to top: simulated PXRD of FFA I (Reference Code = FPAMCA11, blue),' experimental PXRD of treated CSDs (various colors), simulated PXRD of FFA III (Reference Code $=$ FPAMCA, green) ${ }^{,}$and experimental PXRD of PEG (red). 


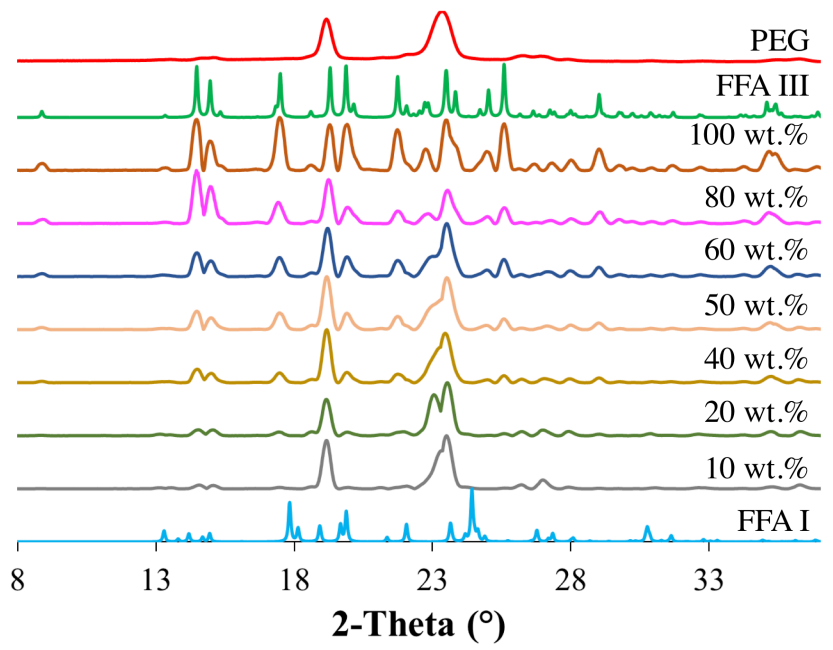

Figure S6. PXRD for CSDs obtained by the solvent evaporation method in methanol using a slow evaporation rate at $60{ }^{\circ} \mathrm{C}$ starting with FFA III. From bottom to top: simulated PXRD of FFA I (Reference Code = FPAMCA11, blue), , experimental PXRD of treated CSDs (various colors), simulated PXRD of FFA III (Reference Code = FPAMCA, green), ${ }^{3}$ and experimental PXRD of PEG (red).

\subsection{Solvent-Fusion Method}

A)

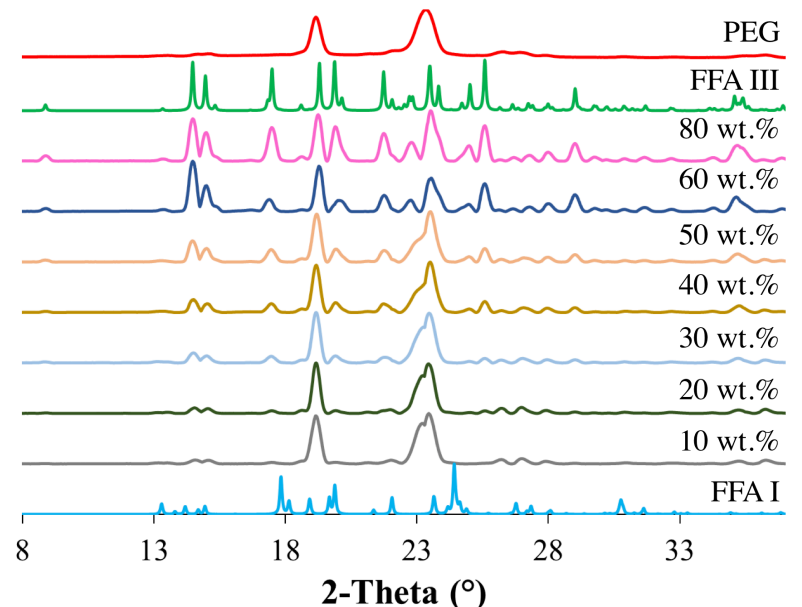

B)

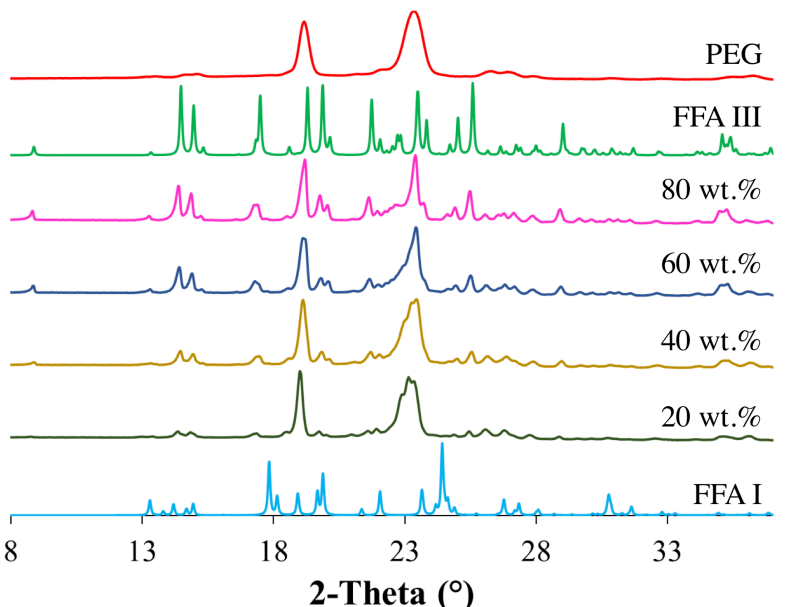

Figure S7. PXRD for CSDs obtained by the solvent-fusion method using methanol starting with A) FFA III or B) FFA I. From bottom to top: simulated PXRD of FFA I (Reference Code = FPAMCA11, blue),' experimental PXRD of treated CSDs (various colors), simulated PXRD of FFA III (Reference Code $=$ FPAMCA, green), ${ }^{3}$ and experimental PXRD of PEG (red). 
A)

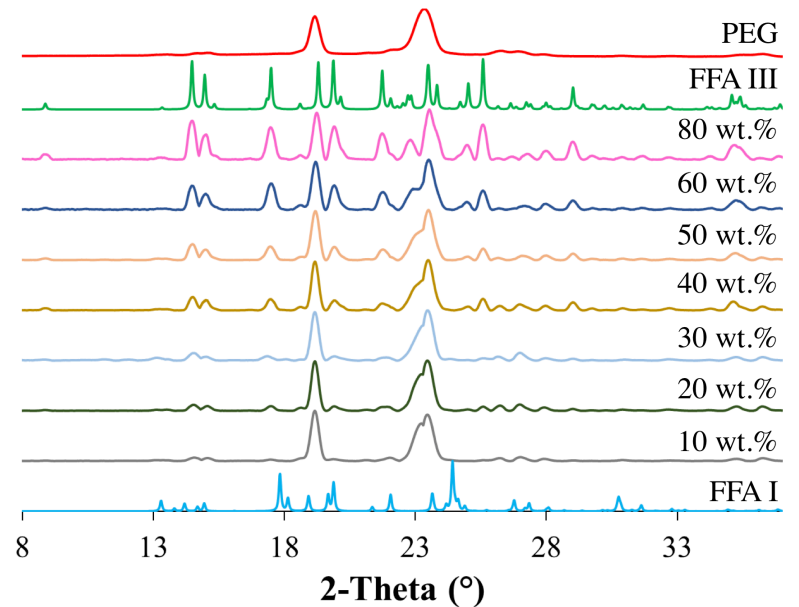

B)

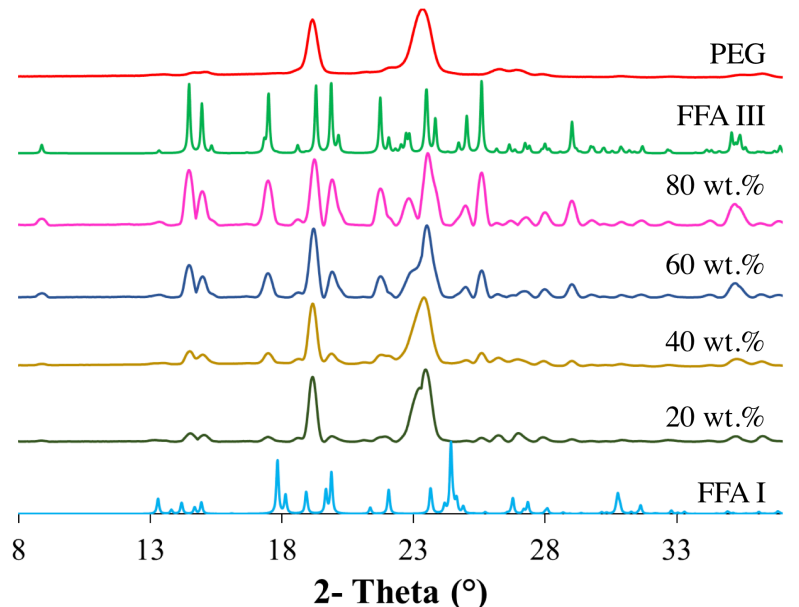

Figure S8. PXRD for CSDs obtained by the solvent-fusion method using ethanol starting with A) FFA III or B) FFA I. From bottom to top: simulated PXRD of FFA I (Reference Code = FPAMCA11, blue), experimental PXRD of treated CSDs (various colors), simulated PXRD of FFA III (Reference Code = FPAMCA, green), and experimental PXRD of PEG (red).

\subsection{Fusion Method}

A)

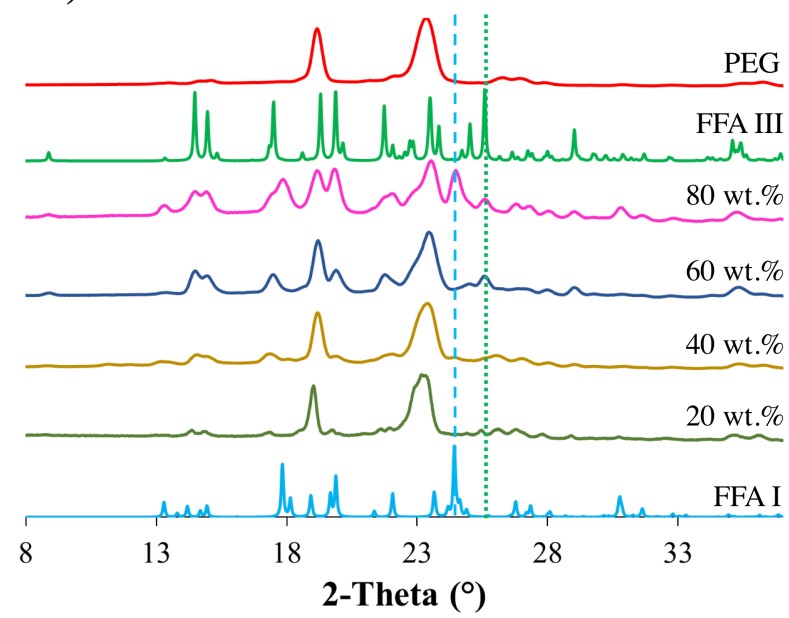

B)

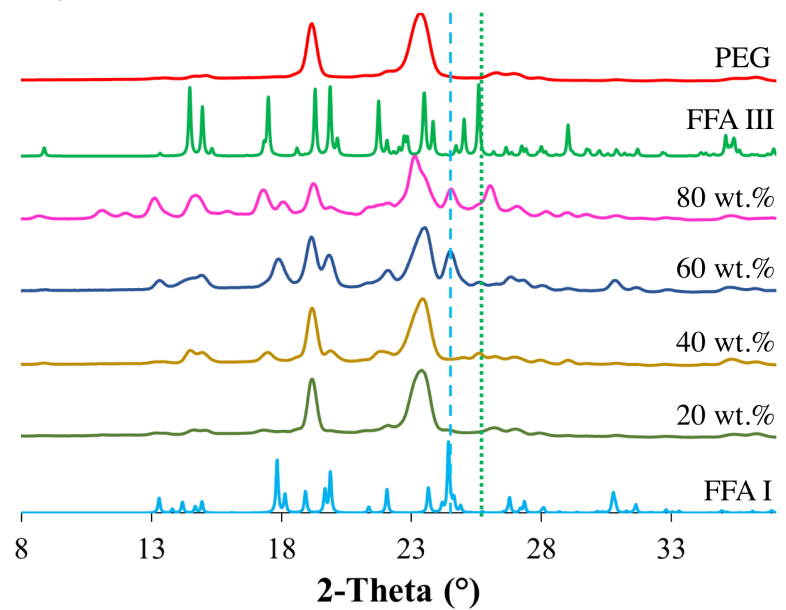

Figure S9. PXRD for CSDs obtained by the fusion method using fast (A) and slow (B) cooling rate starting with FFA I. From bottom to top: simulated PXRD of FFA I (Reference Code = FPAMCA11, blue),' experimental PXRD of treated CSDs (various colors), simulated PXRD of FFA III (Reference Code $=$ FPAMCA, green) ${ }^{3}$ and experimental PXRD of PEG (red). Blue dashed line identifies the characteristic peak of FFA I whereas the green dotted line corresponds to FFA III. 
A)

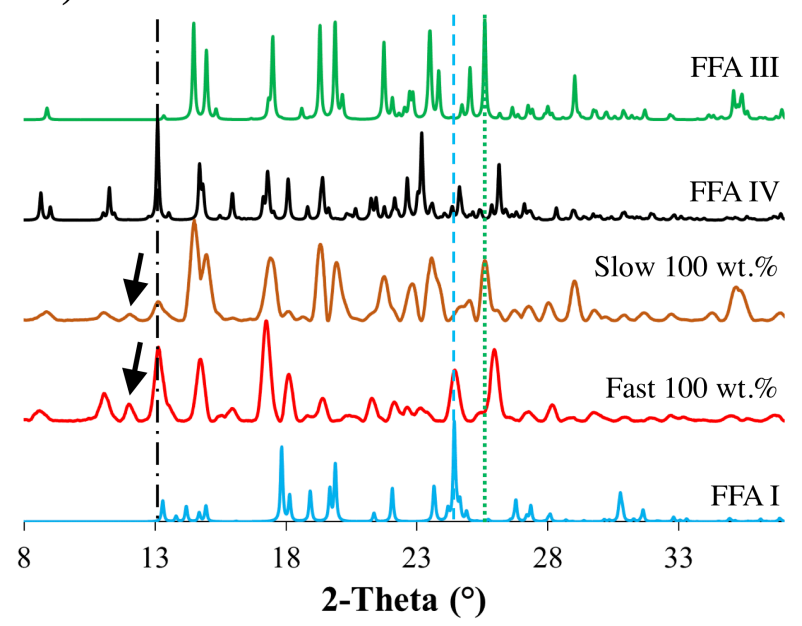

B)

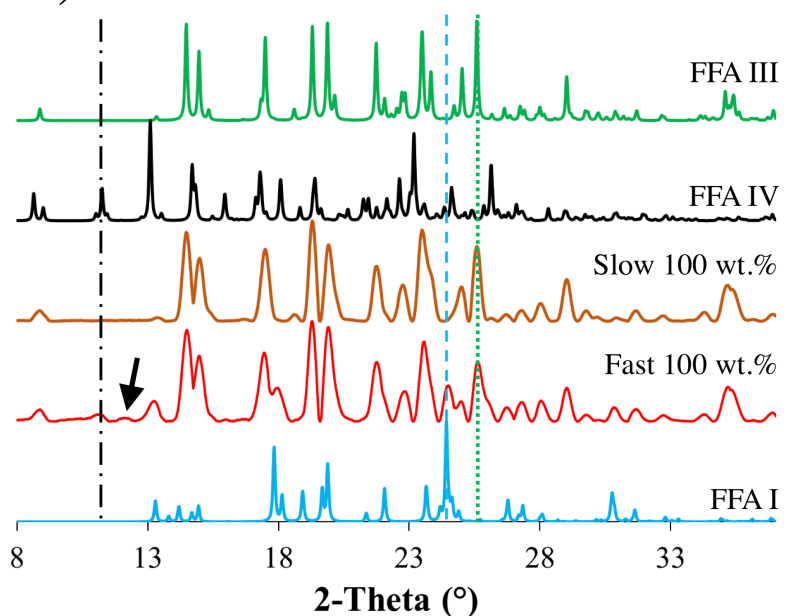

Figure S10. PXRD for $100 \mathrm{wt}$ \% FFA, after the fusion method starting with A) FFA III or B) FFA I. From bottom to top: simulated PXRD of FFA I (Reference Code = FPAMCA11, blue), experimental PXRD of treated sample using a fast cooling rate (red), experimental PXRD of treated sample using a slow cooling rate (brown), simulated PXRD of FFA IV (Reference Code $=$ FPAMCA15, black), ${ }^{\prime}$ and simulated PXRD of FFA III (Reference Code $=$ FPAMCA, green) ${ }^{3}$ Black broken line identifies the characteristic peak of FFA IV, whereas the blue dashed line and green dotted line correspond to FFA I and III, respectively. Black arrow indicates a peak at $11.8^{\circ}$ in 2-theta that possibly corresponds to FFA IX.'

\section{Fourier Transform Infrared (FTIR) Spectroscopy}

Figures S11-S18 show the FTIR spectra of the physical mixtures and the resulting CSDs obtained after each preparation method under each of the experimental conditions. The experimental Infrared spectra of FFA I, FFA III, and PEG are shown also for comparison. 


\subsection{Solvent Evaporation Method}

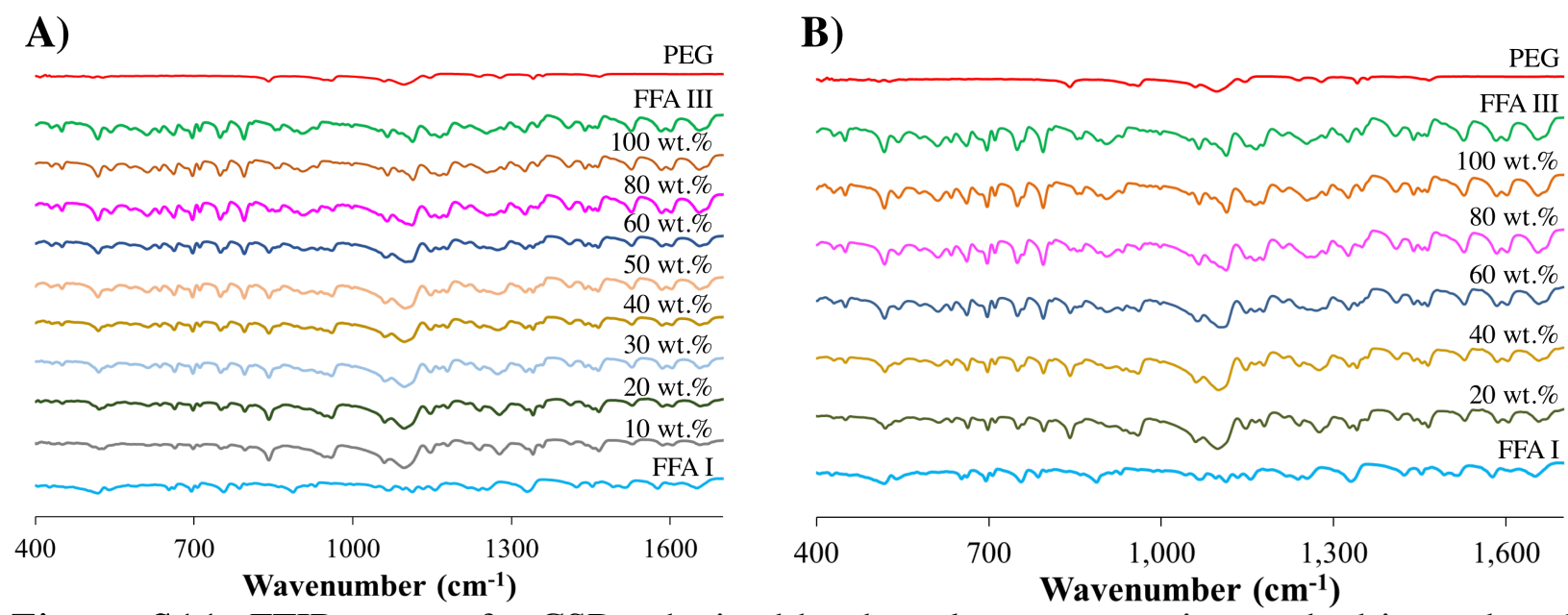

Figure S11. FTIR spectra for CSDs obtained by the solvent evaporation method in methanol using a fast evaporation rate at $40^{\circ} \mathrm{C}$ starting with A) FFA III or B) FFA I. From bottom to top: FTIR spectra of FFA I (blue), treated CSDs (various colors), FFA III (green), and PEG (red).

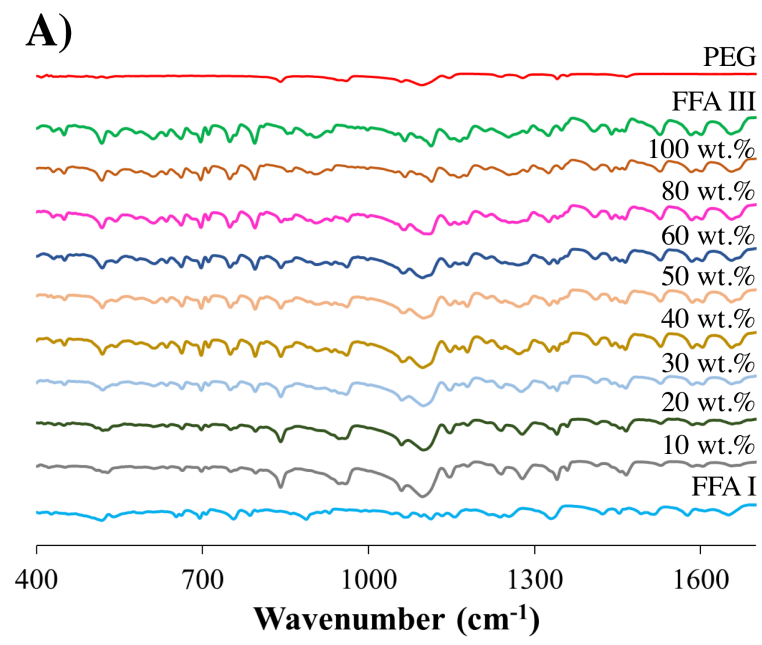

B) PEG

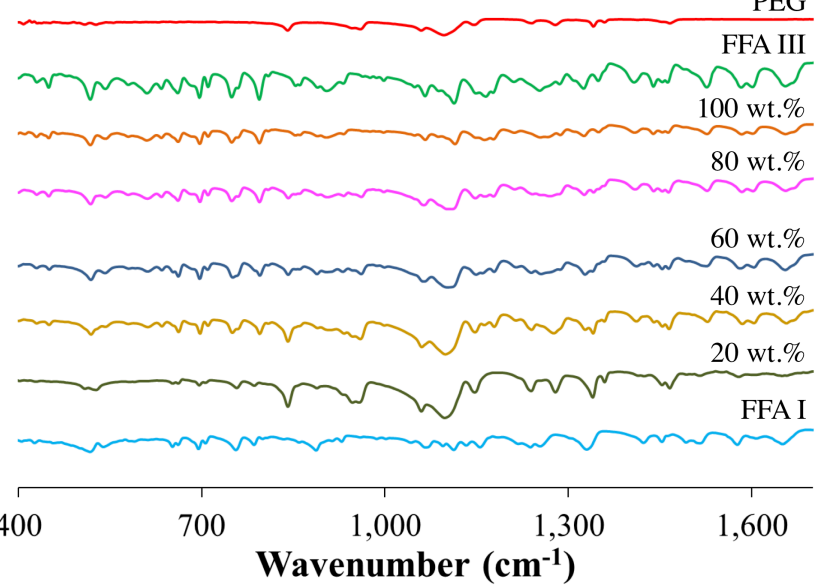

Figure S12. FTIR spectra for CSDs obtained by the solvent evaporation method in methanol using a slow evaporation rate at $40{ }^{\circ} \mathrm{C}$ starting with A) FFA III or B) FFA I. From bottom to top: FTIR spectra of FFA I (blue), treated CSDs (various colors), FFA III (green), and PEG (red). 
A)

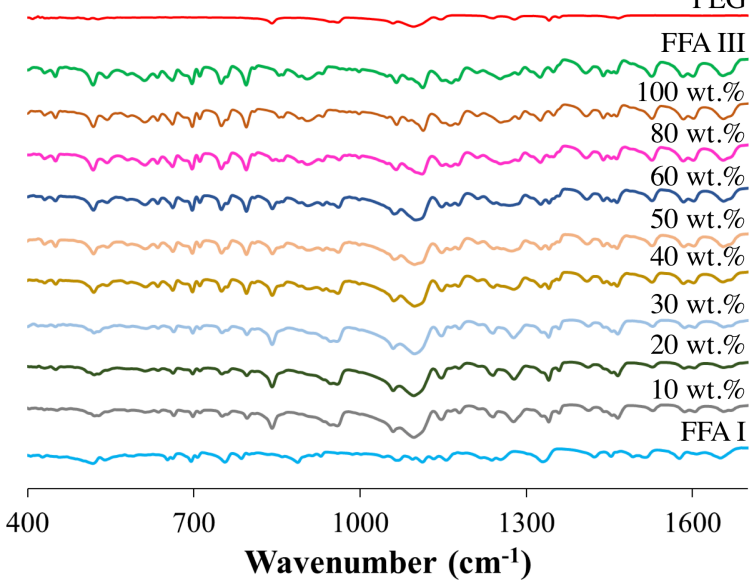

B) PEG

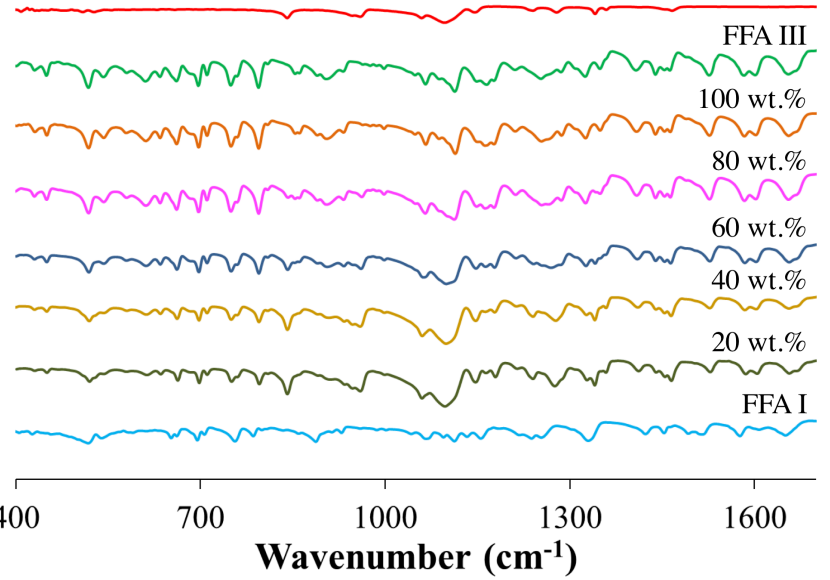

Figure S13. FTIR spectra for CSDs obtained by the solvent evaporation method in ethanol using a fast evaporation rate at $40{ }^{\circ} \mathrm{C}$ starting with A) FFA III or B) FFA I. From bottom to top: FTIR spectra of FFA I (blue), treated CSDs (various colors), FFA III (green), and PEG (red).

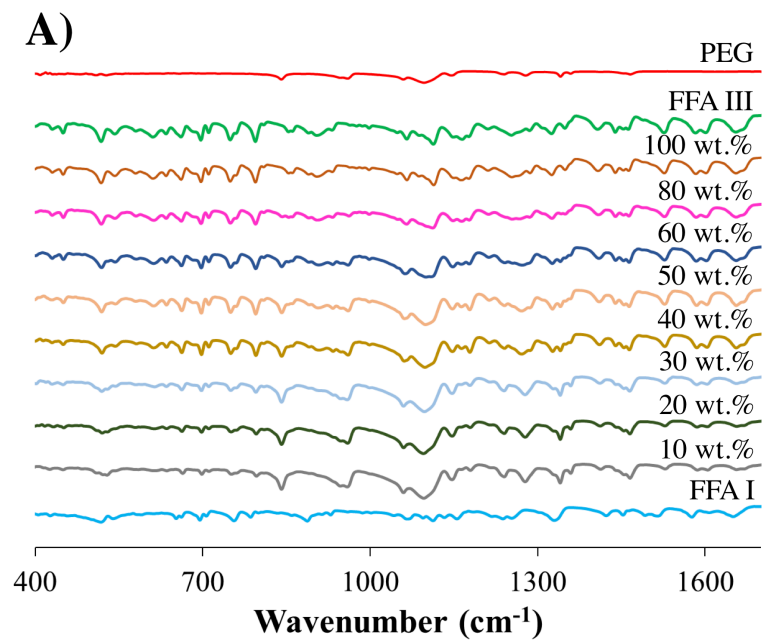

B)

PEG

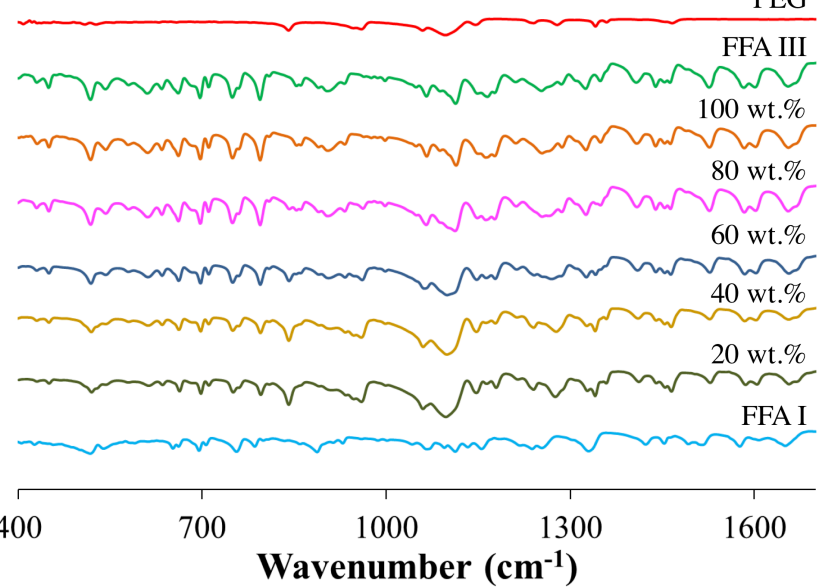

Figure S14. FTIR spectra for CSDs obtained by the solvent evaporation method in ethanol using a slow evaporation rate at $40{ }^{\circ} \mathrm{C}$ starting with A) FFA III or B) FFA I. From bottom to top: FTIR spectra of FFA I (blue), treated CSDs (various colors), FFA III (green), and PEG (red). 


\subsection{Solvent-Fusion Method}
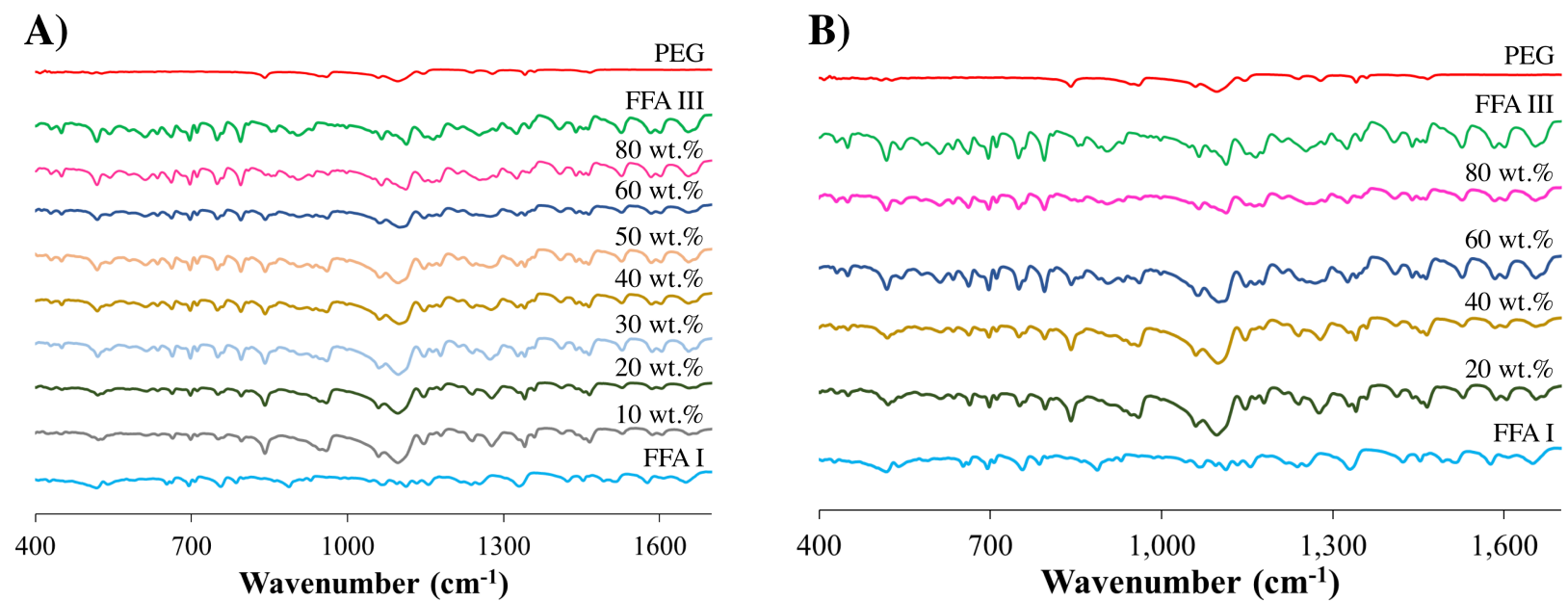

Figure S15. FTIR spectra for CSDs obtained by the solvent-fusion method using methanol starting with A) FFA III or B) FFA I. From bottom to top: FTIR spectra of FFA I (blue), treated CSDs (various colors), FFA III (green), and PEG (red).

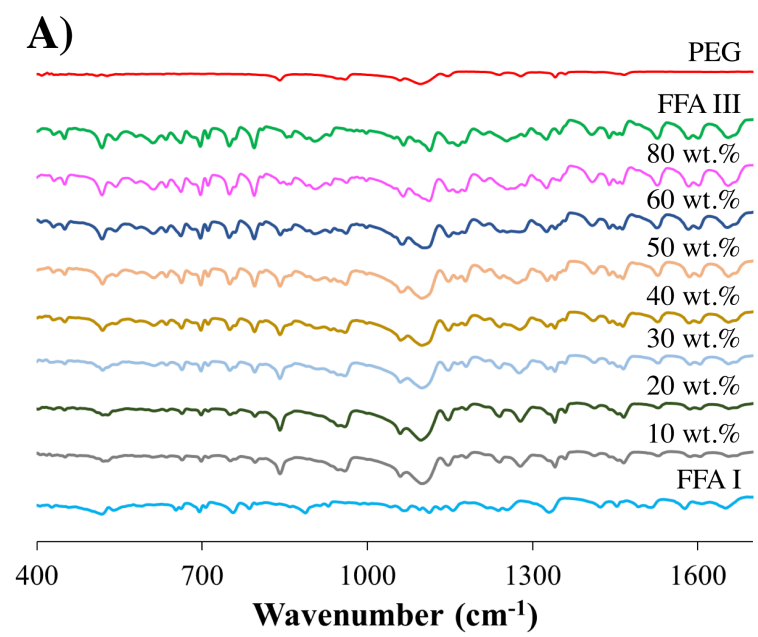

B)

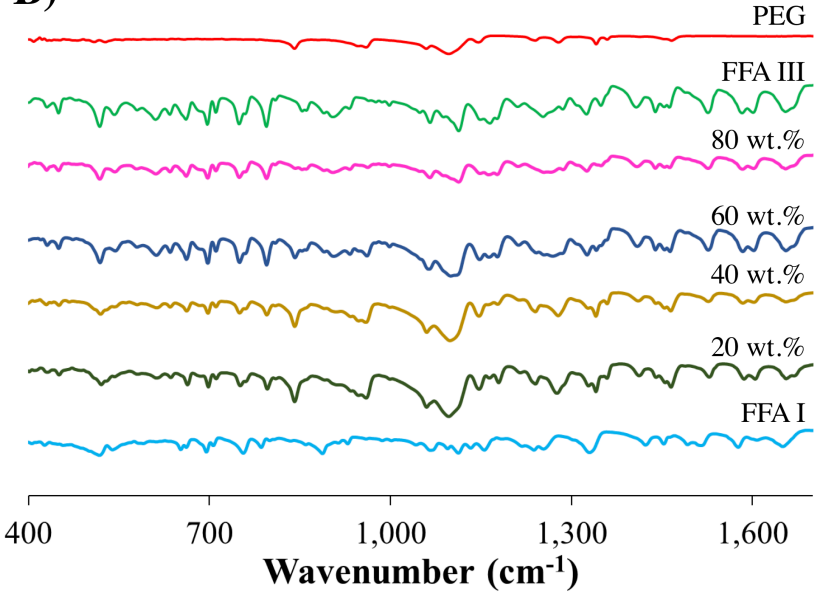

Figure S16. FTIR spectra for CSDs obtained by the solvent-fusion method using ethanol starting with A) FFA III or B) FFA I. From bottom to top: FTIR spectra of FFA I (blue), treated CSDs (various colors), FFA III (green), and PEG (red). 


\subsection{Fusion Method}
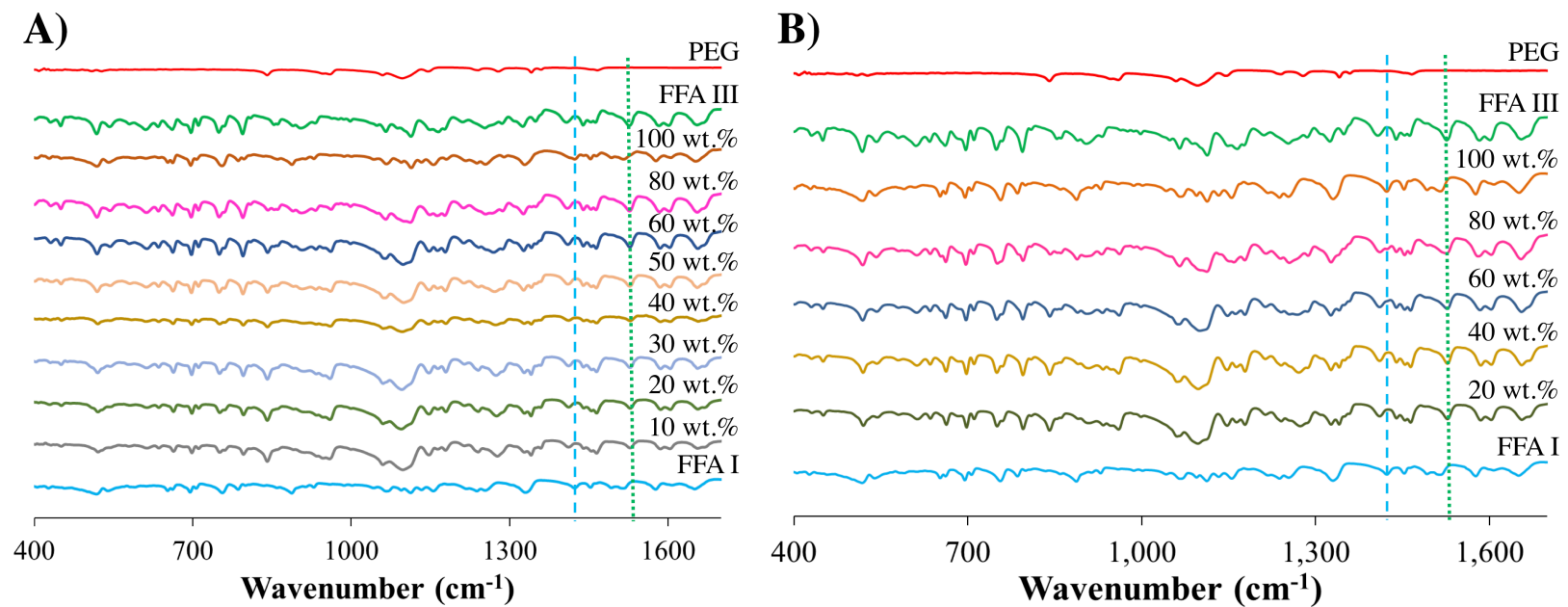

Figure S17. FTIR spectra for CSDs obtained by the fusion method using a fast cooling rate starting with A) FFA III or B) FFA I. From bottom to top: FTIR spectra of FFA I (blue), treated CSDs (various colors), FFA III (green), and PEG (red). Blue dashed line identifies the characteristic peak of FFA I whereas the green dotted line corresponds to FFA III.
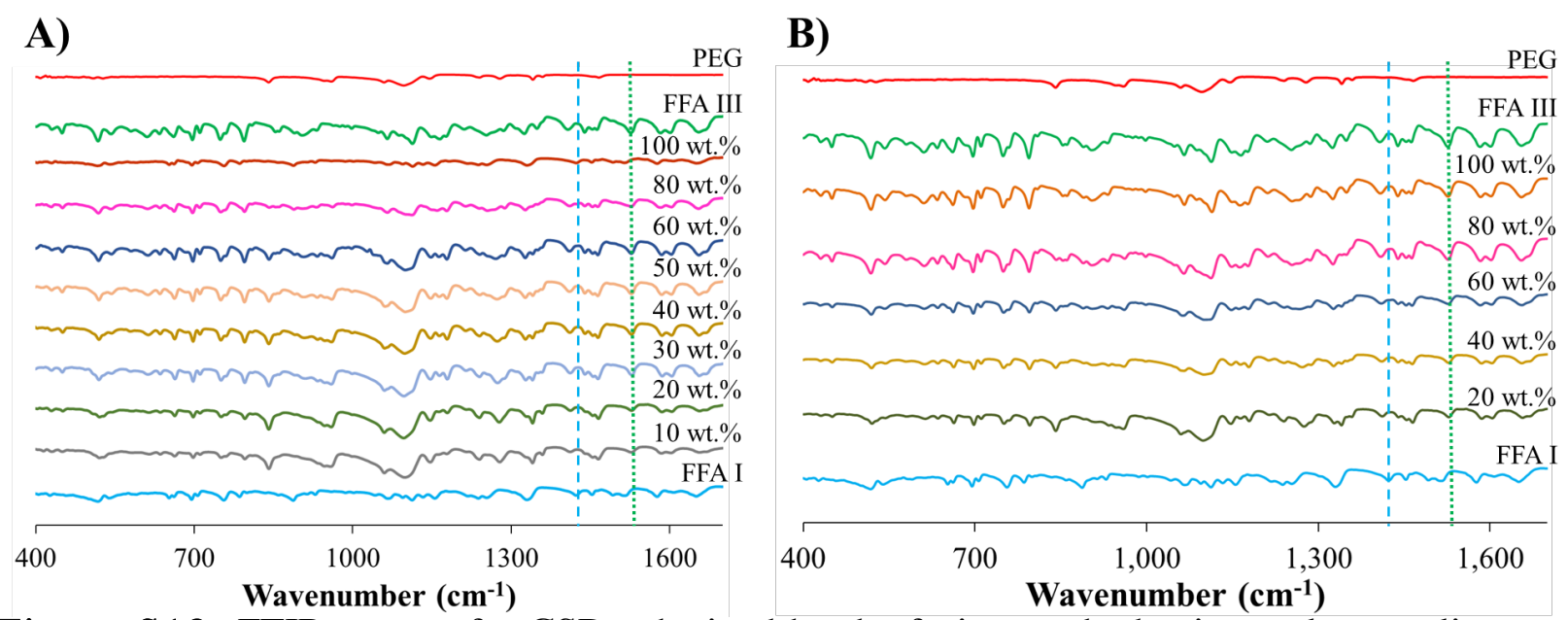

Figure S18. FTIR spectra for CSDs obtained by the fusion method using a slow cooling rate starting with A) FFA III or B) FFA I. From bottom to top: FTIR spectra of FFA I (blue), treated CSDs (various colors), FFA III (green), and PEG (red). Blue dashed line identifies the characteristic peak of FFA I whereas the green dotted line corresponds to FFA III. 


\section{Phase Diagram}

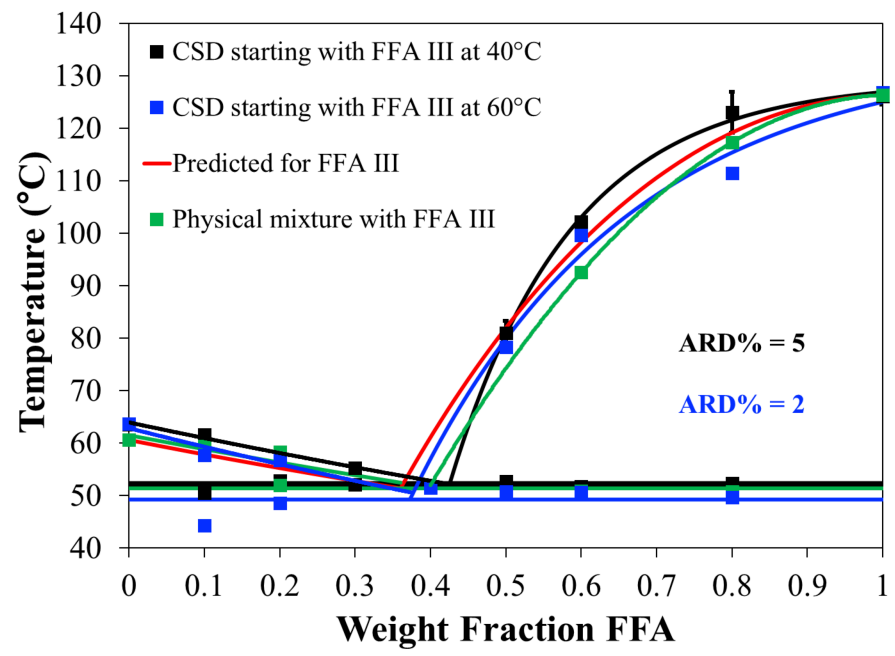

Figure S19. Phase diagrams of CSDs obtained by the solvent evaporation method using the slow evaporation rate starting with FFA III in methanol at $40{ }^{\circ} \mathrm{C}$ (black) and $60{ }^{\circ} \mathrm{C}$ (blue) compared to the predicted Lacoulonche model for FFA III (red) and the physical mixture of FFA IIIPEG (green). If error bars cannot be noticed, these are obstructed by the data points.

\section{Average Relative Deviation (ARD\%)}

Table 2. Summary of average relative deviation (ARD\%) calculated with respect to physical mixtures of FFA III-PEG for all preparation methods, solvents, rates, and temperatures employed. ARD \% given in parenthesis are calculated with respect to FFA I-PEG physical mixture.

\begin{tabular}{|c|c|c|c|c|c|}
\hline \multirow{2}{*}{ Method } & \multirow{2}{*}{ Solvent } & Rate & \multirow{2}{*}{ Temperature } & \multicolumn{2}{|c|}{ ARD\% } \\
\cline { 4 - 6 } & & & $\begin{array}{c}\text { Starting with } \\
\text { FFA III }\end{array}$ & $\begin{array}{c}\text { Starting with } \\
\text { FFA I }\end{array}$ \\
\hline \multirow{3}{*}{$\begin{array}{c}\text { Solvent } \\
\text { Evaporation }\end{array}$} & \multirow{2}{*}{ Methanol } & Fast evaporation & $40{ }^{\circ} \mathrm{C}$ & 5 & 2 \\
\cline { 3 - 6 } & & Slow evaporation & $40{ }^{\circ} \mathrm{C}$ & 5 & 1 \\
\cline { 3 - 6 } & & Slow evaporation & $60{ }^{\circ} \mathrm{C}$ & 2 & - \\
\cline { 3 - 6 } & Ethanol & Fast evaporation & $40{ }^{\circ} \mathrm{C}$ & 5 & $<1$ \\
\cline { 3 - 6 } & Slow evaporation & $40{ }^{\circ} \mathrm{C}$ & 5 & 3 \\
\hline \multirow{2}{*}{$\begin{array}{c}\text { Solvent- } \\
\text { Fusion }\end{array}$} & Methanol & Fast evaporation & $40{ }^{\circ} \mathrm{C}$ & 2 & $<1$ \\
\cline { 3 - 6 } & Ethanol & Fast evaporation & $40{ }^{\circ} \mathrm{C}$ & 2 & 2 \\
\hline \multirow{2}{*}{ Fusion } & - & Fast cooling & - & $5(6)$ & $8(4)$ \\
\cline { 3 - 6 } & - & Slow cooling & - & $3(8)$ & $7(5)$ \\
\hline
\end{tabular}




\section{Supercooling of Spontaneous Nucleation in Fusion Method}

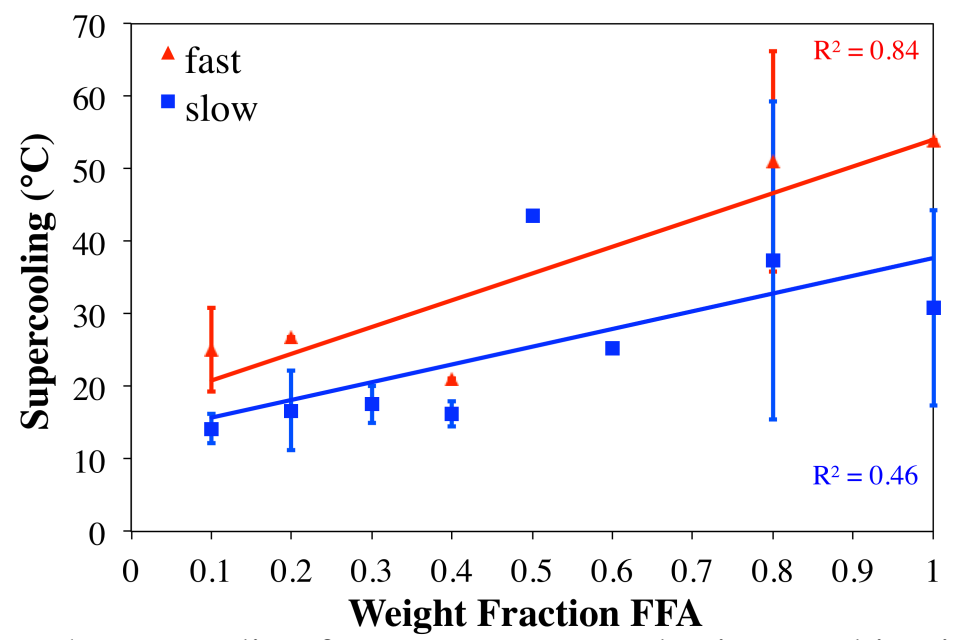

Figure S20. Measured supercooling for spontaneous nucleation resulting in CSDs after undergoing the fusion method using fast (red triangles) and slow (blue squares) cooling..5 If error bars cannot be noticed, these are obstructed by the data points.

\section{References}

(1) López-Mejías, V.; Kampf, J. W.; Matzger, A. J. Nonamorphism in Flufenamic Acid and a New Record for a Polymorphic Compound with Solved Structures. J. Am. Chem. Soc. 2012, 134, 9872-9875.

(2) Polyethylene Glycol [MAK Value Documentation, 1998]. In The MAK-Collection for Occupational Health and Safety; Wiley-VCH Verlag GmbH \& Co. KGaA, 2002; Vol. 10, pp 247-270.

(3) Krishna Murthy, H. M.; Bhat, T. N.; Vijayan, M. Structure of a New Crystal Form of 2$\{[3$-(Trifluoromethyl)Phenyl]Amino\}benzoic Acid (Flufenamic Acid). Acta Crystallogr. 1982, B38, 315-317 DOI: 10.1107/s0567740882002763.

(4) Beckmann, W. Crystallization Basic Concepts and Industrial Applications; Wiley-VCH Verlag GmbH \& Co. KGaA: Weinheim, Germany, 2013.

(5) Myerson, A. S.; Erdemir, D.; Lee, A. Y. Handbook of Industrial Crystallization, 3rd ed.; Cambridge University Press: Cambridge, 2019. 